\title{
MERCADO DE MEL NATURAL: COMPETITIVIDADE NOS PREÇOS DE EXPORTAÇÃO
}

\author{
Maristela Franchetti de Paula ${ }^{1}$, Humberto Angelo ${ }^{2}$, Alexandre Nascimento de Almeida ${ }^{2 *}$, \\ Anadalvo Juazeiro do Santos ${ }^{3}$, João Carlos Garzel Leodoro da Silva ${ }^{3}$ \\ ${ }^{1}$ Universidade Estadual do Centro-Oeste, Guarapuava, Paraná, Brasil - mc1503@yahoo.com.br \\ ${ }^{2}$ Universidade de Brasília, Brasília, Distrito Federal, Brasil - humb@unb.br; alexalmeida @unb.br* \\ ${ }^{3}$ Universidade Federal do Paraná, Curitiba, Paraná, Brasil - ajsantos@ufpr.br; garzel@ufpr.br \\ Recebido para a publicação: 22/04/2015 - Aceito para a publicação: 15/06/2016
}

\begin{abstract}
Resumo
O Brasil, pelo seu clima tropical e ampla área territorial, possui grande potencial para ampliar a sua participação no mercado de mel. A produção de mel, tal como de outros produtos não madeireiros, apresenta vantagens sociais e ambientais, pois proporciona a geração de renda em pequenas propriedades rurais sem a necessidade do desmatamento da floresta. Porém o mercado internacional de mel ainda é pouco explorado pelo Brasil e o seu desenvolvimento ainda carece de informações. Este artigo analisa a competitividade das exportações brasileiras do mel natural por meio do conhecimento das elasticidades de substituição. As relações Brasil-Argentina e Brasil-China, maiores exportadores de mel natural, apontaram diferenciação por produto, pois apresentaram elasticidades substituição inelástica, indicando que os países importadores de mel natural compram tal produto associando-o ao país de origem. Nas relações Brasil-Alemanha, Brasil-México e Brasil-Hungria, a magnitude dos coeficientes da elasticidade de substituição aponta para a existência de competitividade entre o Brasil e os citados países via preço do mel, e não há diferenciação do produto por país de origem. Por outro lado, as relações Brasil-Canadá e Brasil-Espanha apresentam coeficientes de elasticidade de substituição não significativos estatisticamente, o que indica ausência ou baixa competição do mel natural brasileiro com o produto canadense e o espanhol. Nesse caso, conclui-se que, com relação a Argentina, China, Canadá e Espanha, a expansão na participação de mercado via redução de preço mostra-se ineficaz.
\end{abstract}

Palavras-chave: Produtos não madeireiros; mercado internacional; fatia de mercado.

\begin{abstract}
Natural honey market: competitiveness export prices. The Brazil, for its tropical climate and wide territorial area, has great potential to expand their participation in the honey market. The production of honey, such as other nontimber products, have social and environmental benefits, it provides the generation of income in small rural properties without the need for forest deforestation. However, the honey international market is still little explored in Brazil and its development still lacks information. This article analyzes the international competitiveness of Brazilian natural honey export through knowledge of substitution elasticities. The BrazilArgentina and Brazil-China relations, the largest exporters of natural honey, pointed differentiation by product, as presented elasticities inelastic replacement, indicating that natural honey importing countries buy such a product associating it with the country of origin. In relations between Brazil and Germany, Brazil, Mexico and Brazil-Hungary the magnitude of the elasticity of substitution of factors points to the existence of competition between Brazil and the countries mentioned via price of honey, and there is no product differentiation by country of origin. On the other hand, Brazil, Canada and Brazil-Spain relations have no significant substitution elasticity coefficients statistically, indicating absence or low competition in the Brazilian natural honey with the Canadian product and the Spanish. In this case, it is concluded that, with respect to Argentina, China, Canada and Spain to expand market share through price reduction shows ineffective.

Keywords: Non-timber products; international market; market share.
\end{abstract}

\section{INTRODUÇÃO}

Entre os produtos que as florestas propiciam, geralmente a madeira é enfatizada e uma menor atenção é dada aos produtos não madeireiros. A comercialização de produtos não madeireiros, tais como raízes, cascas, semente, tanino, goma, resina, óleo, fruto, cipó e também o mel, muitas vezes é subestimada e acaba se tornando pouco explorada. $\mathrm{O}$ desenvolvimento do mercado de mel natural demanda informações e, nesse sentido, o trabalho abordou a demanda desse produto no mercado internacional, buscando estimar o grau de competitividade entre os seus principais exportadores. 
$\mathrm{O}$ interesse pelo mercado externo do produto mel natural brasileiro é recente e importante para incentivar o setor apícola, que tem papel de destaque no quadro socioeconômico mundial. A relevância desse estudo está no fato de a apicultura ser uma atividade agropecuária que atende aos requisitos do tripé da sustentabilidade: o econômico, o social e o ecológico (SOMMER, 1998). O econômico é o gerador de renda para os produtores; o social intensifica a ocupação de mão de obra familiar no campo, com a diminuição do êxodo rural; e o ecológico se refere à polinização de espécies nativas e cultivadas e a conservação da vegetação, uma vez que não é necessário desmatar para criar abelhas (ALCOFORADO FILHO, 1998).

O mel natural é considerado um dos mais importantes produtos florestais não madeireiros, por ser a apicultura uma atividade conservadora da biodiversidade e, também, uma importante export commodity, juntamente com outros que participam do mercado internacional, como goma arábica, ratam, bambu, cortiça, nozes, cogumelos, óleos essenciais, além de partes de animais e vegetais com fins medicinais (FAO, 2005).

Outro destaque é a crescente participação do mel natural brasileiro no mercado internacional, decorrente da qualidade do produto e da competitividade internacional. O Brasil tornou-se um importante player no mercado mundial, em função dos embargos impostos aos principais exportadores em 2001.

Esse fato incentivou as exportações de mel natural brasileiro, diante de um mercado interno considerado pequeno, quando comparado com a capacidade produtiva do pasto apícola do país. Nesse contexto, o mercado internacional de mel natural é considerado uma alternativa para o desenvolvimento da atividade apícola no Brasil, pois além de possuir baixo impacto ambiental possibilita renda para os proprietários rurais.

Outro fator que facilitou a ampliação do mercado exportador de mel natural foi a queda na produção dos Estados Unidos, principal importador mundial e um dos principais produtores. Em 2000 o país produziu, aproximadamente, 100 mil toneladas, e em 2011 apenas 67 mil toneladas. A Argentina também apresentou redução na sua produção, passando de 93 mil toneladas em 2000 para 59 mil toneladas em 2011 (FAO, 2013).

A evolução da exportação mundial de mel mostra que em 2000 ela era de 367 mil toneladas de mel natural, e que a China e a Argentina, os maiores exportadores, participavam, respectivamente, com 28 e $24 \%$. Naquele ano, o Brasil exportou apenas 269 toneladas. Em 2011, as exportações mundiais chegaram a, aproximadamente, 483 mil toneladas, tendo a China e a Argentina se mantido na liderança, com 21 e $15 \%$, respectivamente. O Brasil alcançou a quarta posição no ranking de maiores exportadores em 2011, com pouco mais de 22 mil toneladas, representando quase 5\% do total exportado no mundo (UN COMTRADE, 2013).

O Brasil tornou-se um dos maiores exportadores mundiais em um curto espaço de tempo, devido às suas características social, econômica e ambiental, que possibilitaram o desenvolvimento da produção apícola. No entanto, segundo Andrade (2005), o potencial apícola, em termos de flora e clima, ainda não foi totalmente explorado e tem grande possibilidade para aumentar a produção, incrementando o agronegócio apícola. Freitas et al. (2004) ressaltaram que o Brasil, pelo seu clima tropical e ampla área territorial, com vasta e variada vegetação, possui características propícias para exploração da apicultura e com o domínio de técnicas apícolas tem condições de se tornar um dos líderes mundiais na produção de mel natural.

Diante desse potencial, faz-se relevante analisar o desempenho das exportações brasileiras. Assim sendo, o objetivo deste estudo foi analisar a competitividade do mel natural brasileiro no mercado internacional no período de 2000 a 2011, considerando a hipótese de que o desempenho das exportações retrata a competitividade de um país, sobretudo no contexto de ampliação das transações comerciais, e que a competitividade do mel natural brasileiro no mercado internacional é semelhante à de seus concorrentes. Esperase que as informações geradas possam auxiliar na formulação de diretrizes de políticas públicas, com a finalidade de ampliar e melhorar o desempenho do produto brasileiro no mercado internacional de mel natural.

\section{REFERENCIAL TEÓRICO}

O processo de demanda pelo produto importado é fundamentada pela teoria microeconômica do consumidor. Segundo essa teoria, o processo de escolha pelo bem importado remete a dois aspectos. O primeiro diz respeito aos produtos homogêneos ou substitutos perfeitos, em que o indivíduo se mostra indiferente quanto à escolha, caso os bens apresentem mesmo nível de preço. É a situação de uma elasticidade substituição infinita entre os produtos. O segundo aspecto refere-se à existência de certo grau de diferenciação entre os bens (PINDYCK; RUBINFELD, 2006).

No que se refere à análise da competitividade e das exportações brasileiras de mel natural, a literatura não é muito contemplativa. Como exemplo de trabalhos, pode-se citar Ricardo (2013), que ressalta que as empresas produtoras de mel em Portugal têm investido em novas instalações, com o intuito de aumentar a competitividade no âmbito nacional e internacional. Além disso, Perosa et al. (2004) identificaram uma vantagem competitiva ligada à política cambial, apontando para a necessidade de coordenação entre a produção e o processamento do mel natural, visando à participação sustentável nos mercados interno e externo. Böhlke e Palmeira (2006), ao estudarem a inserção competitiva do pequeno produtor de mel no mercado internacional, 
concluíram que o Brasil carece de avanços em sua tecnologia, havendo, ainda, a necessidade de investimentos no profissionalismo dos produtores, para a elevação da competitividade do produto e o acréscimo em sua qualidade.

$\mathrm{Na}$ área de Ciências Florestais, podem ser encontrados vários estudos sobre a competitividade, como o de Noce et al. (2008), que pesquisaram a competitividade do Brasil no mercado internacional de aglomerado e concluíram que o efeito competitividade, composto por aspectos endógenos, não favorece o aumento das exportações brasileiras. Já Carvalho et al. (2010), ao confrontarem o desempenho das exportações brasileiras de papel com o de seus principais concorrentes no mercado internacional no período de 1997 a 2006, evidenciaram crescimento das exportações de papel no período analisado, sendo o país o terceiro mais competitivo.

Podem ser destacados também os trabalhos de Silva (2002), que avaliou a competitividade internacional da indústria brasileira de papel de imprimir e escrever sob a ótica da cadeia de valor; Noce et al. (2007), que estudaram o preço relativo e a competitividade no mercado internacional de compensado; Coelho Júnior (2010), sobre a análise econômica de produtos florestais em condições de risco e incerteza; Gomes (2011), que pesquisou a situação atual do Brasil no mercado mundial de polpa celulósica e a competitividade brasileira no segmento, no período de 2000 a 2009; e Soares et al. (2013), que avaliaram a competitividade da produção de celulose em diferentes estados do Brasil.

\section{MATERIAL E MÉTODOS}

Utiliza-se neste artigo o modelo de elasticidade de substituição (ES), que permite captar a diferenciação de produto e de origem. De acordo com Pindyck e Rubinfeld (2004), a elasticidade de substituição capta a capacidade de o bem substituir outro bem na curva de indiferença do consumidor. A baixa elasticidade de substituição indicaria que os méis naturais de dois países não são bons substitutos. Logo, eles seriam diferenciados por país de origem. O caso de elevada elasticidade de substituição no mercado apícola indicaria grande potencial de substituição entre dois países competidores, não havendo, portanto, diferenciação do produto associada ao país de origem. A abordagem do modelo de elasticidade substituição, proposta por Armington (1969), tem sido amplamente explorada em estudos de competitividade no mercado internacional, além de permitir abordar duas pressuposições a respeito da diferenciação do bem.

Entre os estudos que fazem uso desse método, citam-se Silva e Dutton (1991), que analisam a competitividade do suco de laranja congelado. Angelo (2001); Brasil (2003) estudaram, respectivamente, a competitividade das exportações brasileiras de madeiras e painéis. Almeida et al. (2010) também aplicam essa metodologia em estudo da competitividade no mercado internacional de madeiras tropicais.

A fundamentação teórica microeconômica da elasticidade de substituição baseia-se na seguinte relação na forma logarítmica:

$$
\log (q 1 / q 2)=\alpha+\varepsilon \log (p 1 / p 2)+\mu
$$

em que: $q_{1}=$ quantidade de mel brasileiro $(\mathrm{kg})$ demandado no momento $\mathrm{t}$ para o mundo; $q_{2}=$ quantidade de mel de um país concorrente $(\mathrm{kg})$ demandado no momento $t$ para o mundo; $\varepsilon_{t}=$ elasticidade de substituição; $p_{1}=$ preço do mel brasileiro (US\$) demandado no momento t para o mundo; $p_{2}=$ preço do mel de um país concorrente (US\$) demandado no momento $t$ para o mundo; e $\mu=$ termo estocástico.

As hipóteses testadas são $\mathrm{H}_{0}: \varepsilon=0$ e $\mathrm{H}_{1}: \varepsilon \neq 0$. Em outros termos: se estatisticamente existe relação de substituição da demanda de exportação do mel natural entre dois países no mercado internacional. Assim, a redução no preço internacional do mel natural do país provoca aumento de sua exportação e queda nas exportações do país concorrente, ceteris paribus, e vice-versa. Os resultados entendidos como valores positivos e significativos configuram relações competitivas entre os países exportadores, e os negativos e significativos caracterizam que os produtos se complementam no mercado exportador. Os valores $\varepsilon=0$ significam que os importadores não diferenciam o produto de ambos os países.

A estimativa da ES (Equação 1) foi realizada por meio do método dos mínimos quadrados ordinários (MQO), e as hipóteses foram testadas pelo teste t. Foram admitidas elasticidades significativas com uma probabilidade de erro de até $10 \%$.

As hipóteses testadas são $\mathrm{H}_{0}: \varepsilon=0$ e $\mathrm{H}_{1}: \varepsilon \neq 0$. Em outros termos: se estatisticamente existe relação de substituição entre duas origens de mel natural no mercado internacional. Assim, a redução no preço internacional de mel de um dado país provoca aumento de sua exportação e queda nas exportações de seu concorrente, ceteris paribus, e vice-versa. Os resultados são entendidos em módulo: os valores entre 0 e 1 configuram relações inelásticas, e aqueles acima de 1, elásticas.

Como países concorrentes, foram testados os principais exportadores mundiais de mel natural, no período de 2000 a 2011. Assim, o resultado positivo da elasticidade objetivou identificar a existência de bens

FLORESTA, Curitiba, PR, v. 46, n. 3, p. 363 - 369, jul. / set. 2016.

Paula, M. F. de et al.

ISSN eletrônico 1982-4688 
substitutos, enquanto o valor negativo representou bens complementares, ao passo que a resposta igual a zero demonstrou que os bens são independentes. Além disso, as relações com alta elasticidade de substituição permitem concluir que os produtos possam ser substituíveis e altamente competitivos no mercado (ANGELO, 2001; BRASIL, 2003).

O modelo considera as seguintes pressuposições:

1. elasticidades-preço direta e cruzada da demanda indireta e cruzada dos bens são iguais;

2. elasticidade renda idêntica para os produtos;

3. oferta de importação perfeitamente elástica, de modo que os preços são predeterminados;

4. elasticidade substituição constante e negativa, ou seja, são menores que zero, logo, os produtos são substitutos e competitivos;

5. a demanda por importação de um bem é função da sua elasticidade de substituição.

A base de dados utilizada são as estatísticas anuais disponibilizadas pelo site da Unite Nations Comtrade (UN Comtrade) e Food and Agriculture Organization (FAO), no período de 2000 a 2011. As informações coletadas foram: volume de exportações (em mil toneladas) de mel natural do Brasil e dos principais concorrentes - China, Argentina, México, Alemanha, Canadá, Hungria e Espanha -; preço (FOB) médio de exportação de cada nação. O preço médio foi obtido pelos quocientes entre valores exportados de mel natural (em US\$1,000) e quantidades exportadas de mel natural.

\section{RESULTADOS E DISCUSSÃO}

Nesta seção, são mostrados os resultados encontrados para o modelo de diferenciação do Brasil em relação a China, Argentina, México, Alemanha, Canadá, Hungria e Espanha. Esses países detêm as maiores parcelas das exportações mundiais de mel natural. Analisa-se também competitividade entre Brasil e os referidos países, vis a vis.

O resultado dos modelos ajustados é apresentado na tabela 1.

Tabela 1. Elasticidade substituição para o modelo de diferenciação do Brasil com os mercados de mel natural dos principais países exportadores no período de 2000 a 2011.

Table 1. Substitution elasticity for differentiation model among Brazil with natural honey markets of the main exporting countries from 2000 to 2011 .

\begin{tabular}{lc}
\hline Países & Elasticidade de substituição \\
\hline China & $0,075^{\mathrm{NS}}$ \\
Argentina & $-0,787^{*}$ \\
México & $-2,297^{*}$ \\
Alemanha & $-1,764^{*}$ \\
Canadá & $-1,436^{\mathrm{NS}}$ \\
Hungria & $-2,859^{*}$ \\
Espanha & $-1,427^{\mathrm{NS}}$ \\
\hline$*=$ significativo a $10 \%$ de probabilidade; ${ }^{\mathrm{NS}}=$ corresponde a não \\
significativo.
\end{tabular}

As informações contidas na tabela 1 confirmam a especificação teórica. Todos os coeficientes têm os sinais esperados, à exceção da China. Observe-se que:

1. A elasticidade de substituição da demanda das exportações de mel natural do Brasil com Argentina se comporta com um baixo grau de substituição, comparativamente.

2. Com relação aos demais países estudados, as elasticidades de substituição foram grandes e a ordem de grandeza variou de $-1,76$ a $-2,86$.

3. A evidência indica a existência de competição por diferenciação e país de origem para o mel natural do Brasil com a Argentina e competitividade via preço com México, Alemanha e Hungria.

As elasticidades de substituição que se estatisticamente significativas a $10 \%$ de probabilidade mostraram-se altas para os países estudados, com exceção da Argentina. A baixa elasticidade obtida entre Brasil e Argentina sugere a diferenciação dos produtos associada aos países de origens. A elasticidade de substituição para Brasil-México, Brasil-Alemanha e Brasil-Hungria mostrou-se relativamente elevada e superior à unidade em módulo, o que caracterizou um alto grau de substituição.

Os coeficientes de valores maiores que |-1| apontam que há competitividade entre Brasil-México, Brasil-Alemanha e Brasil-Hungria via preço dos produtos e que não há diferenciação do produto por país de 
origem. Nesse sentido, o mel exportado pelo Brasil é considerado bom substituto do mel natural do México, da Alemanha e da Hungria. A queda de $10 \%$ nos preços relativos das exportações brasileiras de mel natural promove elevação de, respectivamente, $23,0 \%, 17,7 \%$ e $28,6 \%$ do volume exportado pelo Brasil em relação às exportações de México, Alemanha e Hungria.

Como Argentina e China estão nos primeiros postos do ranking de maiores exportadores do mercado de mel natural, é de se esperar que possuam estrutura produtiva mais capacitada para atender aos mercados, ofertando produtos de maior nível de diferenciação. De fato, empresas líderes desenvolvem estratégias que visam à crescente diferenciação de seus principais produtos, o que ocasiona segmentação crescente do mercado. A concorrência é centrada em atributos que diferenciam os produtos, induzindo ao desenvolvimento de estratégias de comercialização vinculadas a altos gastos em publicidade e à conquista de novos canais de comercialização (ESTEVES FILHO, 2001; BORGES; LEONARDI, 2010).

Ward e Boynton (2010) destacaram a importância da publicidade no mercado de mel, destacando a importância de informar a categoria e características do produto, a fím de alcançar as especificidades dos seus mercados consumidores, seja ele ligado ao segmento alimentício ou de matéria-prima para outros setores industriais.

De forma distinta, define-se a relação competitiva entre Brasil e China. A elasticidade substituição apresentou sinal incoerente com a teoria, além de não ter apresentado significância estatística. Esse resultado revela que a relação de competitividade entre Brasil e China é regida pela diferenciação do mel natural ligada ao país de origem. Da mesma forma se comporta a relação competitiva entre Brasil e Canadá e Brasil e Espanha, onde a elasticidade de substituição apresenta os sinais coerentes com a teoria, mas sem significância estatística. Os países importadores compram associando o produto ao país de origem, sugerindo que cada país tem um produto diferente, seja pela qualidade e/ou confiabilidade.

Segundo Phipps (2016), a diferenciação do mel chinês pode ser explicada por uma política agressiva nos últimos três anos, focada no desenvolvimento e aplicação de novas tecnologias para produção do mel chinês, conhecida como tecnologia de resina. Segundo o autor, essa tecnologia permite: 1) disfarçar o tipo de mel do país de origem pelas metodologias científicas atuais; 2) remover não só o pólen, mas também antibióticos e resíduos, reduzindo assim os riscos para importadores, exportadores e embaladores; 3) remover os componentes químicos que dão cor ao mel, com isso permitindo que países tropicais e semitropicais ampliem suas exportações de mel branco; 4) remover os componentes químicos de mel que acrescentam sabor e aroma. Além dessa questão tecnológica, Phipps (2016) também destacou uma agressiva política de dumping exercida pela China que pode contribuir para diferenciar o seu produto no mercado.

Em suma, nota-se que a concorrência do mel natural brasileiro é menor em relação aos principais exportadores mundiais, a Argentina e a China, com os quais a competitividade do mel natural brasileiro ocorre pela diferenciação e pela origem do produto. Com relação ao México, Alemanha e Hungria, a competitividade se acentua no mercado internacional com uma maior sensibilidade a preço do produto nacional.

A diferença entre o mel brasileiro e o argentino se deve ao desenvolvimento e profissionalização da apicultura na argentina e à sua longa tradição no mercado internacional. Conforme Perez et al. (2004), a produtividade média brasileira varia de 18 a 20 quilos de mel por colmeia por ano, enquanto a Argentina alcança 38 quilos/colmeia/ano. Além disso, diferentemente da Argentina, o mercado interno têm sido o principal destino da produção brasileira de mel e responsável pela estruturação da atividade, o que limita a competitividade do Brasil em concorrer com os principais players no mercado internacional (PEROSA et al., 2004).

A competição entre Brasil-Canadá e Brasil-Espanha revela baixa presença ou ausência de competitividade do Brasil no mercado de mel natural com esses países, devido às mudanças nos preços relativos do mel natural brasileiro não afetarem de forma significativa as quantidades exportadas em relação aos referidos países.

\section{CONCLUSÕES}

- O Brasil é competitivo no mercado internacional de mel natural via relação de preço com os países México, Alemanha e Hungria, e pela diferenciação e origem do produto com a Argentina.

- Com os demais países estudados (China, Canadá e Espanha), o mel natural brasileiro não compete nem por diferenciação e pela origem do produto, nem via relação de preço.

- Embora o Brasil possua grande potencial para geração de riquezas no mercado mundial de mel, o país ainda carece de políticas para a profissionalização do setor e orientação para o mercado externo, como, por exemplo, estabelecimento de linhas de crédito específicas, investimentos em laboratórios e pesquisas e empenho para a adequação da produção nacional às normas internacionais. 


\section{REFERENCIAS}

ALCOFORADO FILHO, F. G. Sustentabilidade do semiárido através da apicultura. In: CONGRESSO BRASILEIRO DE APICULTURA, 12., 1998, Salvador, BA. Anais... Salvador: UFBA/SBB, 1998. 61 p.

ALMEIDA, A. N. de; ÂNGELO, H.; SILVA, J. C. G. L. da; HOEFLICH, V. A. Mercado de madeiras tropicais: substituição na demanda de exportação. Acta Amazônica, Manaus, v. 40, n. 1, p. 119-126, 2010.

ANDRADE, R. C. P. Apicultura - Mundo, Brasil, Paraná. Curitiba: Secretaria de Estado da Agricultura e do Abastecimento, 2005.

ÂNGELO, H. A influência do desmatamento e do manejo florestal na oferta de madeiras tropicais da Amazônia brasileira. FAO/TCP/BRA/8923, 2001.

ARMINGTON, P. S. The geographic pattern of trade and the effects of price changes. International Monetary Fund Staff Papers, Washington, v. 16, n. 2, p. 179-199, 1969a.

BÖHLKE, P. B.; PALMEIRA, E. M. Inserção competitiva do pequeno produtor de mel no mercado internacional. Revista Acadêmica de Economia, Uberlândia, v. 72, p. 1-7, 2006.

BORGES, J. A. R.; LEONARDI, A. Mel natural - Brasil no mercado mundial. FGV, Agroanalysis, São Paulo, maio, 2010.

BRASIL, A. A.; ÂNGELO, H.; SILVA, J. C. E. G. da; LACOWICK, P. G. Substituição nas exportações brasileiras de painéis de madeira. Floresta e Ambiente, Brasília, v. 10, n. 2, p. 1-10, 2003.

CARVALHO, K. H. A.; COSTA, C. C. M.; SOARES, N. S.; SILVA, M. L. Desempenho das exportações brasileiras de papel. Scientia Forestalis, São Paulo, v. 28, n. 36, p. 263-271, 2010.

COELHO JUNIOR, L. M. Análise econômica de produtos florestais em condições de risco de incerteza. 2010. Tese (Doutorado em Engenharia Florestal) - Universidade Federal de Lavras.

ESTEVES FILHO, M. Competitividade, conceituação e fatores determinantes. Brasília: BNDES, 1991. 26 p. Coordenação. BOLETINS.

FOOD AGRICULTURE AND ORGANIZATION (FAO). Conservation and management of pollinators for sustainable agriculture - the international response. In: FREITAS, B. M.; PEREIRA, J. O. P. (Ed.). Solitary bees: conservation, rearing and management for pollination. Fortaleza: Imprensa Universitária. p. 19-25. 2004.

.Global Forest Resources Assessment 2005. Roma, Itália, 2005. Disponível em <http://www.fao.org/>. Acesso em 10/01/13.

Disponível em <http//www.fao.org.br>. Acesso em 20/12/2013.

FREITAS, D. G. F.; KHAN, A. S.; SILVA, L. M. R. Nível tecnológico e rentabilidade de produção de mel de abelha (Apis mellifera) no Ceará. Revista de Economia Rural, Brasília, v. 42, n. 1, p. 171-188, 2004.

GOMES, L. M. B. Segmento brasileiro de polpa celulósica: evolução, competitividade e inovação. 2011. Tese (Doutorado em Engenharia Florestal) - Universidade de São Paulo.

NOCE, R.; SILVA, M. L.; MENDES, L. M.; SOUZA, A. L.; SILVA, O. M.; OLIVEIRA, J. M.; CARVALHO, R. M. A. Preço relativo e competitividade no mercado internacional de compensado. Revista Cerne, Lavras, v. 13, n. 1, p. 51-56, 2007.

NOCE, R.; SILVA, M. L.; SOUZA, A. L.; SILVA, O. M.; MENDES, L. M.; CARVALHO, R. M. M. C.; VALVERDE, S. R. Competitividade do Brasil no mercado internacional de aglomerado. Revista Árvore, Viçosa, v. 32, n. 1, p. 113-118, 2008.

PEREZ, L. H.; RESENDE, J. V. de; FREITAS, B. B. de. Exportações brasileiras de mel natural no período 2001-2003. Revista Informações Econômicas, São Paulo, v. 34, n. 6, p. 28-37, 2004.

PEROSA, J. M. Y.; ARAUCO, E. M. R.; SANTOS, M. L. de A; ALBARRACÍN, V. N. Parâmetros de competitividade do mel brasileiro. Informações Econômicas, São Paulo, v. 34, n. 3, p. 41-48, 2004.

PHIPPS, R. International honey market. American Been Journal, p. 391-395, 2016. Disponível em: <http://www.ahpanet.com/page/IntlHoneyMarket>. Acesso em: 23 abril 2016. 
PINDYCK, R. S.; RUBINFELD, D. L. Econometria: modelos \& previsões. Rio de Janeiro: Elsevier, 2004. 726 p.

Microeconomia. 6 ed. São Paulo: Pearson Prentice Hall, 2006.

RICARDO, S. I. A. A exportação do mel português: um estudo exploratório sobre as motivações, barreiras e estratégias. 2013. Dissertação (Mestrado em Economia) - Instituo Superior de Contabilidade e Administração do Porto.

SILVA, C. L. Competitividade internacional da indústria de papel de imprimir e escrever brasileira sob a ótica da cadeia de valor. 2002. Tese (Doutorado em Economia) - Universidade Federal de Santa Catarina.

SILVA, O. M.; DUTTON JR., J. C. O Mercado internacional de suco de laranja concentrado congelado: um modelo com produtos diferenciados. Revista de Economia e Sociologia Rural, Brasília, v. 29, n. 4, p. 353-371, 1991.

SOARES, N. S.; SILVA, M. L.; REZENDE, J. L. P.; JACOVINE, L. A. G.; VALVERDE, S. R. Competitividade da produção de celulose em diferentes estados do Brasil. Revista Cerne, Lavras, v. 19, n. 2, p. 297-305, 2013.

SOMMER, P. G. O. Desenvolvimento da apicultura brasileira. In: CONGRESSO BRASILEIRO DE APICULTURA, 12., 1998, Salvador (BA). Anais... 1998. 173 p.

UN COMTRADE - United Nations Commodity Trade Statistics Database. UN Comtrade database, 2013.

WARD, R.; BRUCE, B. U. S. honey supply chain: structural change, promotions and the China connection. International Journal of System Dynamics, Hershey, v. 1, p. 13-25, 2010. 